\title{
Comment on the Article "Cupping Therapy: An Overview from a Modern Medicine Perspective": The Complications of Cupping Are Preventable
}

Dear Editor,

With great interest, we read the article of Aboushanab et al. [1] entitled "Cupping Therapy: An Overview from a Modern Medicine Perspective" in the journal of Acupuncture and Meridian Studies 11 (3), 2018. In this article, cupping is classified with a different aspect. In a part of this article, the adverse effects of cupping are mentioned and divided into two categories: preventable and non-preventable. Kubner's phenomenon, vasovagal attack, headache, dizziness, and nausea are classified in the non-preventable group, while according to the sources of Persian medicine, these complications can be prevented.

In the Persian medicine, it is believed that digestion of food and its transformation into body tissues occurs during four digestive stages: The first digestion is in the stomach; the second digestion is in the liver, the third digestion is in the vessels, and the fourth digestion is in the tissues $[2,3]$. Persian medicine scholars believed that cupping in the interscapular area weakens the stomach. It is stated in Kholasat-al-Hekmah (Summary of wisdom) that if cupping is done immediately after eating, it will disrupt the first and second digestion stages so inappropriate humors will move towards the place of cupping and cause vitiligo (Baras) [4]. Also, in those who have a history of gastrointestinal diseases due to bile dominance, cupping causes more weakness of the stomach and bile movement, so nausea, dizziness, headache, and symptoms of vasovagal attack may occur [5]. Of course, this problem does not occur in healthy people without digestive problems. Persian scholars believed that if bile prevails in the stomach, the resulting vapors will rise to the brain and cause the mentioned complications. To solve this complication, the scholars advise such people not to do cupping when they are hungry and to eat some light food such as quince or apple jam with bread half an hour before cupping, and to drink some pomegranate juice or lettuce and some vinegar after cupping. This suppresses the bile vapors and prevents these side effects $[3,4]$.

The authors of this letter also agree with Aboushanab that these adverse effects of cupping are infrequent but would be rare if the points mentioned by Persian scholars are considered. In our clinical experience, we have concluded that if the indications of cupping are correctly diagnosed and done according to the opinion of Persian medical scholars, cupping will not cause serious complications [5].

Preventable complications of cupping are also based on the performance of the practitioner, which will not occur if the correct principles and rules are observed. El Sayed et al. [6] in his article, declares that cupping itself does not cause any side effects and all its complications are preventable.

\section{CONFLICT OF INTEREST}

The author declares no conflict of interest.

\section{ORCID}

Maryam Moghimi,

https://orcid.org/0000-0003-1656-0873

Gholamreza Kordafshari,

https://orcid.org/0000-0001-9052-9626

Hoorieh Mohammadi Kenari,

https://orcid.org/0000-0003-0658-5284

\section{REFERENCES}

1. Aboushanab TS, AlSanad S. Cupping therapy: an overview from a modern medicine perspective. J Acupunct Meridian Stud 2018;11:83-7.

2. Avicenna H. Al-Qanoon fi al-Tibb (The Canon of Medicine). Beirut: Dare Ehia Attorath Al Arabi, 2005.

3. Jorjani I. Treasure of the KhwarazmShah. Qom: Institute of Natural Resuscitation, 2011.

4. Aghili Khorasani MA. The Summary of Wisdom (KholāsaAlHekma). Theran: Institute of History of Islamic and Complementary Medicine, 2006.

5. Gholamreza K, Mohammad Reza Shams A, Mansoor K, Mohammad ME, Ismaeel N, Maryam M, et al. Cupping therapy can improve the quality of life of healthy people in Tehran. J Tradit Chin Med 2017;37:558-62.

6. El Sayed SM, Al-quliti AS, Mahmoud HS, Baghdadi H, Maria 
RA, Nabo MMH, et al. Therapeutic benefits of Al-hijamah: in light of modern medicine and prophetic medicine. Am J Med Biol Res 2014;2:46-71.

Maryam Moghimi ${ }^{1}$, Gholamreza Kordafshari ${ }^{2}$, Hoorieh Mohammadi Kenari ${ }^{3, *}$

${ }^{1}$ Masiha Teb Shomal Knowledge-based cooperation, Sari, Iran, ${ }^{2}$ School of Persian Medicine, Tehran University of Medical Sciences,

Tehran, Iran, ${ }^{3}$ Research Institute for Islamic and Complementary
Medicine, School of Persian Medicine, Iran University of Medical

Sciences, Tehran, Iran

Correspondence to. Hoorieh Mohammadi Kenari

Research Institute for Islamic and Complementary Medicine, School of

Persian Medicine, Iran University of Medical Sciences, Tehran, Iran

E-mail: mohammadikenari.h@iums.ac.ir

Received November 2, 2020, Accepted December 27, 2020

\section{Response to Moghimi et al. Classification of Cupping Therapy Adverse Events: An Update}

\section{Dear Editor,}

The response by Moghimi et al. [1] to our published review entitled "Cupping therapy: An overview from a modern medicine perspective." was received with high interest to reply to it [2]. Moghimi et al. [1] claimed that all cupping therapy adverse events were preventable. We are not with agreement with this claim.

An adverse event was defined by the World Health Organization (WHO) as: "An injury related to medical management, in contrast to complications of diseases" [3] and classified into preventable and non-preventable adverse events [3]. So, every harm or injury in relation to cupping therapy is considered an adverse event and the classification of adverse events was applied to it. Furthermore, WHO defined preventable adverse event as: "An adverse event caused by an error or other type of systems or equipment failure." [3]. So, every adverse event which is not related to error of the practitioner or the system or equipment failure is non-preventable adverse event. Dizziness, nausea, kobner's phenomenon and vasovagal attack were adverse events which reported and they were not related to the errors of practitioners or failure of system or equipment [4].

Our review discussed cupping therapy from a modern medicine perspective which may differ from the perspective of any traditional medicine system. Furthermore, there is a need for high quality clinical trials to confirm or deny the advices which were given by Moghimi et al. [1].

Author of this reply suggested an update for the previously published classifications of cupping therapy adverse events which were published in 2016 [4], and 2018 [2], and was represented in Fig. 1. Preventable cupping therapy adverse events were noticed to be mainly local while non-preventable cupping adverse events were mainly systemic.

Finally, there is a need for more clinical trials regarding the
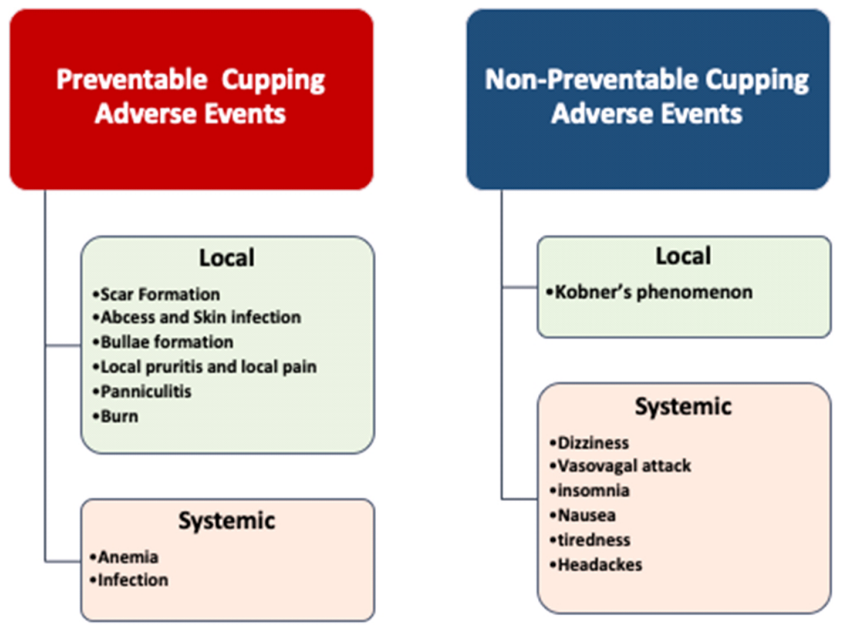

Fig. 1. Updated classification of cupping therapy adverse events.

safety and adverse events of cupping therapy. All researchers are encouraged to report in full details any adverse event of cupping therapy clinical trials. A new high quality systematic review of cupping therapy safety and adverse events is recommended.

\section{CONFLICT OF INTEREST}

The author declares no conflict of interest.

\section{ORCID}

Tamer S. Aboushanab, https://orcid.org/0000-0002-4184-0431

\section{REFERENCES}

1. Moghimi M, Kordafshari G, Kenari HM. Comment on the 